\begin{tabular}{c} 
International Journal of Engineering \& Technology, $7(3.2)(2018) 329-333$ \\
International Journal of Engineering \& Technology \\
SPC \\
Website: www.sciencepubco.com/index.php/IJET \\
Research paper \\
\hline
\end{tabular}

\title{
Crowd Funding as a Tool for Financing the Construction of Social Facilities
}

\author{
Liana Ptashchenko ${ }^{1 *}$, Maya Chechelashvili \\ ${ }^{1}$ Poltava National Technical Yuri Kondratyuk University, Ukraine \\ ${ }^{2}$ Georgian Technical University, Georgia \\ *Corresponding Author E-Mail:Lianaptaschenko63@Meta.Ua
}

\begin{abstract}
The article analyzes the social state of countries experiencing economic convergence in the European Community on the basis of rating indicators of the level of happiness of the population. It is noted that the main problem of weak socialization in these countries is inadequate financing of measures for implementing me general social policy, including construction of social facilities. The article substantiates the idea that it is possible to solve the problem of financing the construction of social facilities with the help of crowd funding, which is not popular in this industry yet. Based on the study of crowd funding, the purpose of the article is to determine the organizational mechanism for the successful implementation of social projects with the help of crowd-hosting platforms. Since the basis of crowded platforms development in the social sphere is trust and motivation, the article suggests using crowd-sourcing, which would help a wider circle of the public pay attention to the social project.

The authors are the first to form an organizational mechanism for supporting and implementing projects for the construction of social facilities with the help of crowd-funding platforms and proposed a mixed technology for implementing a social project; this technology is an advanced combination of creating experimental objects and active implementation of projects through advertising and crowd-sourcing. The support for the project on the crowd-diving platform was described by the authors as crowd-shipping development. The emphasis was placed on the need to train active and enterprising people in technologies and prospects of crowd finding for projects of construction of social facilities, as well as the population awareness of crowd funding advantages and possibilities for the development of regions (territories) of the country. It is noted that this will allow creating objective conditions for the formation of citizens' attitudes towards the socialization of relations in society, envolving the population into social activity, and forming a social culture in society.
\end{abstract}

Keywords: construction of social facilities, crowd funding, crowd funding project, crowd sourcing, development, technology implementation of social projects.

\section{Introduction}

After the collapse of the USSR, for most of the countries of the former socialist camp, which chose the path of European development, the problem of economic convergence with the EU countries arose. Often this process is painful, because governments use unpopular economic methods among the population.

The analysis of the experience of those countries that successfully passed the economic convergence and joined the EU shows that the people of these countries have experienced economic and social shocks, which is natural in the period of convergence with the developed countries of the European Union. However, the governments of the countries tried to smooth these shocks with adequate economic and social policies.

For example, countries experienced such financial and energy shocks:

- financial shocks in the field of pricing - inflation in the EU transition countries in $2008-2009$, average of $10 \%$, while in the euro area - only about $2 \%$;

- exchange rate shocks - another type of financial convergence shock for the economies of the new EU member states, related to the fulfillment of the requirements for the stabilization of the foreign exchange rate as defined by the Maastricht Agreement;
- increased dependence on external financing and intensification of domestic lending to the economy;

- energy shocks - shock changes in energy prices for the newly integrated EU countries were simultaneously exacerbated by exogenous shocks associated with the trend of rising primary energy prices in world markets [1].

But to emphasize - to smooth out these shocks, the governments of the countries intensively lent to business, supported and facilitated economies renewal based on energy efficiency and innovation, actively developed social infrastructure and state social policy [2]. In those countries that are currently experiencing economic convergency, the situation looks worse [3].

For example, when trying to take measures on the economic convergence of Ukraine with the EU, the government uses unpopular tools of state regulation, or vice versa, it stops such regulation in socially important spheres (this concerns price and tariff regulation).

Despite the declared social orientation of economy development, frequently changing Ukrainian governments pay little attention to the development of certain social facilities in the regions.

The quality and state of the social sphere does not meet the population needs, the standard of living is low, state support for the unprotected strata of the population is very low. This is evidenced by the data of the World Happiness Report 2017, according to 
which happiness of the population in the World Ranking of such countries as: Azerbaijan, Georgia and Ukraine have a figure below the average of 155 countries included in this rating (Table 1).

Table 1: Rating of countries that have experienced economic and social shocks of convergence, according to the level of happiness of the population in 2017 [4]

\begin{tabular}{|c|l|c|}
\hline RATING & \multicolumn{1}{|c|}{ COUNTRY } & INDEX \\
\hline 16 & Germany & 6.951 \\
\hline 23 & Czech Republic & 6.609 \\
\hline 40 & Slovakia & 6.098 \\
\hline 46 & Poland & 5.973 \\
\hline 47 & Uzbekistan & 5.971 \\
\hline 52 & Lithuania & 5.902 \\
\hline 54 & Latvia & 5.850 \\
\hline 59 & Turkmenistan & 5.822 \\
\hline 60 & Kazakhstan & 5.819 \\
\hline 66 & Estonia & 5.611 \\
\hline 73 & Serbia & 5.395 \\
\hline 77 & Croatia & 5.293 \\
\hline 78 & Kosovo & 5.279 \\
\hline 83 & Montenegro & 5.237 \\
\hline 85 & Azerbaijan & 5.234 \\
\hline 105 & Bulgaria & 4.714 \\
\hline 121 & Armenia & 4.376 \\
\hline 125 & Georgia & 4.286 \\
\hline 132 & Ukraine & 4.096 \\
\hline
\end{tabular}

According to the table, it is clear that among the countries of the former socialist camp that have experienced or are experiencing economic convergence, Ukraine is in the last place in terms of the level of happiness of the population.

It should be noted that in the social policies of Azerbaijan, Georgia and Ukraine, there is an increase in the development of socia infrastructure. This is achieved, first of all, through the development of private property in these areas. However, the quality and quantity of providing services in social institutions do not always meet the needs and demand of the population. At the same time the main problems are the lack of financial resources and the unwillingness of business to invest in non profitable social facilities (for example, the construction and maintenance of boarding schools, old people's homes, rehabilitation centers for people with disabilities, etc.).

This shows the need to facilitate the implementation of social projects that are able to mitigate the negative consequences of economic convergence.

Since the governments of the countries do not have time (or do not consider this a priority), it is possible to support social projects by the efforts of socially indifferent citizens, using the financial resources of a large number of social investors.

The authors of the article believe that it is possible to solve the problem of financing the construction of social facilities using such investment tools as crowd funding, which has not become popular in this industry yet. In this context, the aim of the article is to investigate innovative sources of financing the construction of social facilities and to determine the algorithm for successful implementation of social projects using crowd-aming platforms.

\section{Main Body}

Social policy issues are examined in the works of J. Eliasop, $\mathrm{H}$. Singer, T. Campboll, V. Krasovsky, P. Samuelson, G. Hedtkamp, E. Libanova, V. Skuratovsky, V. Kutsenko and other scientists. Studies of crowd funding were covered in the scientific works of such scientists and specialists as I. Vasilchuk, K. Poltorak, D. Howe, N. Lobjanidze, L. Shvets and others. At the same time, the issue of financing social facilities, which is a complex and urgent problem, is not sufficiently studied. After all, most social institutions provide services in the non-profit sector of the economics, their activities are not profitable, but aimed at obtaining a social effect. At the same time, for the activation of construction and successful operation, social facilities require significant capital investment [5]. At the same time, regional features of the economic and social state of the territories should be considered.

Each region has certain specific features that distinguish it from all others. This specificity should be taken into account while making decisions on the formation and development of regional social facilities. It is necessary to build and develop the social sphere, depending on such territorial features:

- the presence of significant disproportions in the concentration of social facilities;

- degree of concentration of industrial facilities and harmful industries;

- sector peculiarities of the territory - the degree of agricultural development, industry, services and so on;

- level of medium and small business development;

- unemployment rate;

- demographic condition;

- Incomes of the population in comparison with the national average.

At the same time, the following factors are important ones that influence the development and formation of the social sphere and social policy:

- economic-positive trends in the country's economic development, territories, favorable investment climate;

- institutional-legislative stability, the presence of powerful social institutions;

- scientific and technical - progress in science and technology, state support of scientifically and economically sound social projects;

- socially-public - positive trends in state social policy, strengthening social guarantees, improving the quality of life;

- intellectual - the level of intellectual capital, professionalism of staff, social activity of citizens in public processes.

We believe that all factors (with signs of constructiveness) can positively influence the social orientation of national economies, but all of them depend on the active and favorable development of the first two - economic and institutional.

Even with the presence of a favorable economic and institutional environment, social investors should be aware that the goal of social investment is not so much to make a profit as to improve the level and quality of life of people by meeting their material, spiritual and social needs.

Considering the positive experience of social investment in developed countries, it should be noted that the G-7 countries pay much attention to the expansion of the global social investment market. Periodically, in different countries, the Task Force of Social Investments is going to study the possibilities of social investments in different countries. The Social Impact Investment Task Force consists of two representatives from each of the G-7 nations, one from the public sector and one from civil society. In 2015, as the Social Impact Investment Taskforce was expanded into the Global Impact Investment Steering Group of 13 member states plus the EU: Australia, Brazil, Canada, France, Germany, India, Israel, Italy, Japan, Mexico, Portugal, USA, European Union ${ }^{1}$. The meetings consider issues of possible partnership between the state, the social sector and social investors to strengthen social influence on the development of states. Innovations in the social sphere that investors and social entrepreneurs can use to improve their image, the efficiency of using the potential that offers social investments, while stimulating new ways of solving the social problems.

Crowd-funding refers to such forms of financing the social projects. Many refer to crowd-funding as a «new phenomenon». However, this is not so new as we think; as a concept, it existed for several centuries. The novelty lies in technology and thinking, which give the process of «crowd financing» a new impetus, [6] allow solving seemingly unsolvable financial problems. The most famous world crowd-funding platform is kick-starter, which was

${ }^{1}$ Global social impact investment steering group, available online: http://www.socialimpactinvestment.org/ 
established in 2009 [7]. This platform is primarily aimed at the implementation of innovative projects. Ideas related to technical inventions, music, software, video and many others are placed here.

Also popular is the Indiegogo world-wide crowd-funding platform. There are no restrictions on the type of project and the geographical location of the company. The most successful areas on this platform are projects that improve the way of life and the surrounding eco-environment. This platform is quite attractive for the implementation of social projects. If you need to have the status of a local resident to authorize on Kick-starter and the possibility of accumulating funds, then for Indiegogo - only a bank account. In addition, the option of «endless crowd- funding», has recently appeared on Indiegogo when the deadline for completing the campaign is not specified. The most successful projects were Indiegogo smartphone Ubuntu Edge (more than \$ 13 million), Hive Flow Hive (11320000 \$), Clever helmet Skully (\$2800000), Family robot Jibo (\$2300000).

There are also other crowd-funding platforms, which place special projects. For example, the implementation of musical, literary projects contribute to Pledge-Music, Unbound and Distrify, and the creation of a startup - Fundable, Crowd-cube and Seedrs. Placing projects on the platforms GoFundMe, Razoo, Charitable allows you to raise funds to fund ideas and projects, to solve personal problems.

Today, many countries of the world are creating their own platform funding platforms. For example, in Ukraine, there were several of their own crowd-funding platforms. This became possible due to the revival of patronage traditions, the gradual abandonment of post-Soviet habits of paternalism, excessive consumer behavior and passive civic position [8].

These are such platforms as «Spil'nokosht - Big Idea», «NaStarte», «Idea Box», «Travel Starter». The analysis of the projects, which are placed on the Ukrainian croweding platforms, made it possible to conclude that crowdshipping activity in Ukraine is not developing actively. So, on the «Na-Starte» platform there are proposed the categories, which are designed mostly for small commercial projects (table 2).

Table 2: Projects placed on the Ukrainian crowd funding platform «NaStarte»

\begin{tabular}{|l|l|l|}
\hline Heading & $\begin{array}{l}\text { Number of placed } \\
\text { projects }\end{array}$ & $\begin{array}{l}\text { Number of projects that } \\
\text { have collected the re- } \\
\text { quired amount }\end{array}$ \\
\hline Video & 18 & 4 \\
\hline Food & 3 & 1 \\
\hline Theater & 0 & 0 \\
\hline IT-technologies & 1 & 0 \\
\hline Games & 5 & 2 \\
\hline Music & 19 & 4 \\
\hline Publications & 14 & 4 \\
\hline Technologies & 16 & 5 \\
\hline Art & 9 & 1 \\
\hline Sport & 2 & 0 \\
\hline Ecology & 0 & 0 \\
\hline A photo & 0 & 0 \\
\hline Fashion & 0 & 0 \\
\hline Innovations & 0 & 0 \\
\hline
\end{tabular}

* Summarized by the authors

In Georgia, there are no own crowd-hosting platforms yet - projects (usually ideas in the field of culture and art) are placed on Kick-starter or Indiegogo.

Dreamers.az and Uguruyogur.az have been created in Azerbaijan for collective fund-raising in order to finance projects in the field of art [9].

Thus, in the analyzed countries there are almost no crowd-drawing projects for the construction of social facilities, although the problems of financing such facilities are quite relevant. This fact can become a powerful impetus to start working on creation of crowdhosting social platforms and activation of initiatives on working at projects for the construction of social facilities. After all, large banks are not prone to risk, and the venture capital sector sees the construction industry as an investment with a relatively high risk, a small return on investment compared to high-tech industries.

As the study showed, the growth of IT technologies and the emergency of crowded framing platforms represent new, alternative opportunities for construction entrepreneurs to fill the financing gap in the development of new ideas and social projects.

These new platforms provide largely untapped opportunities for construction entrepreneurs and social companies to seek investment capital for their new ideas from the socially active part of the population. For example, using the crowd funding platform Crowd-cube, the startup cleantech in the UK raised $£ 762,000$ from 535 equity investors in just two days to support the development of floor tiles capable of generating energy from pedestrians.

At the same time, in each of the projects that will be hosted on crowd-funding platforms, it is necessary to explain why this project deserves investment, what it will be useful for society, how to improve the social climate and how the investments will return to donors. In the context of the fact that the problem of trust and motivation is the key to the development of crowd-sporting platforms in the social sphere, it is advisable to use crowd-sourcing, which would help a wider circle of the public pay attention to the proposed social project. In addition, with the help of crowdsourcing, the authors and developers of projects can attract the population of the territory to collect ideas on the successful implementation of projects, improve their projects, make them attractive and socially useful.

Eric von Hippel calls crowd-sourcing «innovation based on the consumer» [10]. We agree with this thesis, since crowd-sourcing involves the transfer of some production or management functions to an indefinite circle of people in order to solve socially significant problems by volunteer forces with the help of modern information technologies. The mechanism of crowd-sourcing has long been used successfully in business and politics, and very little - to solve social problems. However, crowd-sourcing can be used in the social sector, innovations and other areas of human activity. At the same time, these types of tools are used to solve problems: voting, finding solutions, collecting information, discussing the problem, testing, questioning, creative competition, etc. [11].

Crowd-sourcing has been used for many years in the construction sector in the form of competitions (for example, design for some of the most iconic buildings, including the Sydney Opera House). Nevertheless, it has not yet been widely disseminated with the support of crowd-hosting projects and new business ideas in the construction of social facilities.

The study allowed us to form an organizational mechanism for supporting and implementing projects for the construction of social facilities using crowd-funding platforms (Figure 1).

In the presented organizational mechanism, the authors and executors of the project are kind of crowd-funder developers, proceeding from the essence of development in general and the approaches of scientists to the consideration of trust activities [12].

Implementing a successful project for the construction of a social facility, crowd-funding development should identify the technologies of such implementation that are most suitable for this region, take into account the features of the project and its social purpose. In these technologies, several types are distinguished (Table 3). The most successful, in our opinion, can be the mixed technology proposed by the authors of the introduction of a social project, which is a combination of the creation of experimental objects (spot) and implementing projects activity with advertising and crowd-sourcing (aggressive).

At the same time, the important place is taken by the state regulation of social investment using crow-funding, which should be implemented on the basis of the principles of social justice and social and economic efficiency. The purpose of state regulation of crowd-funding activities in the sphere of construction of social facilities should include such aspects as achieving a balance in the interaction of the state, investors and consumers in the process of raising the level and quality of life in the country and its regions. 


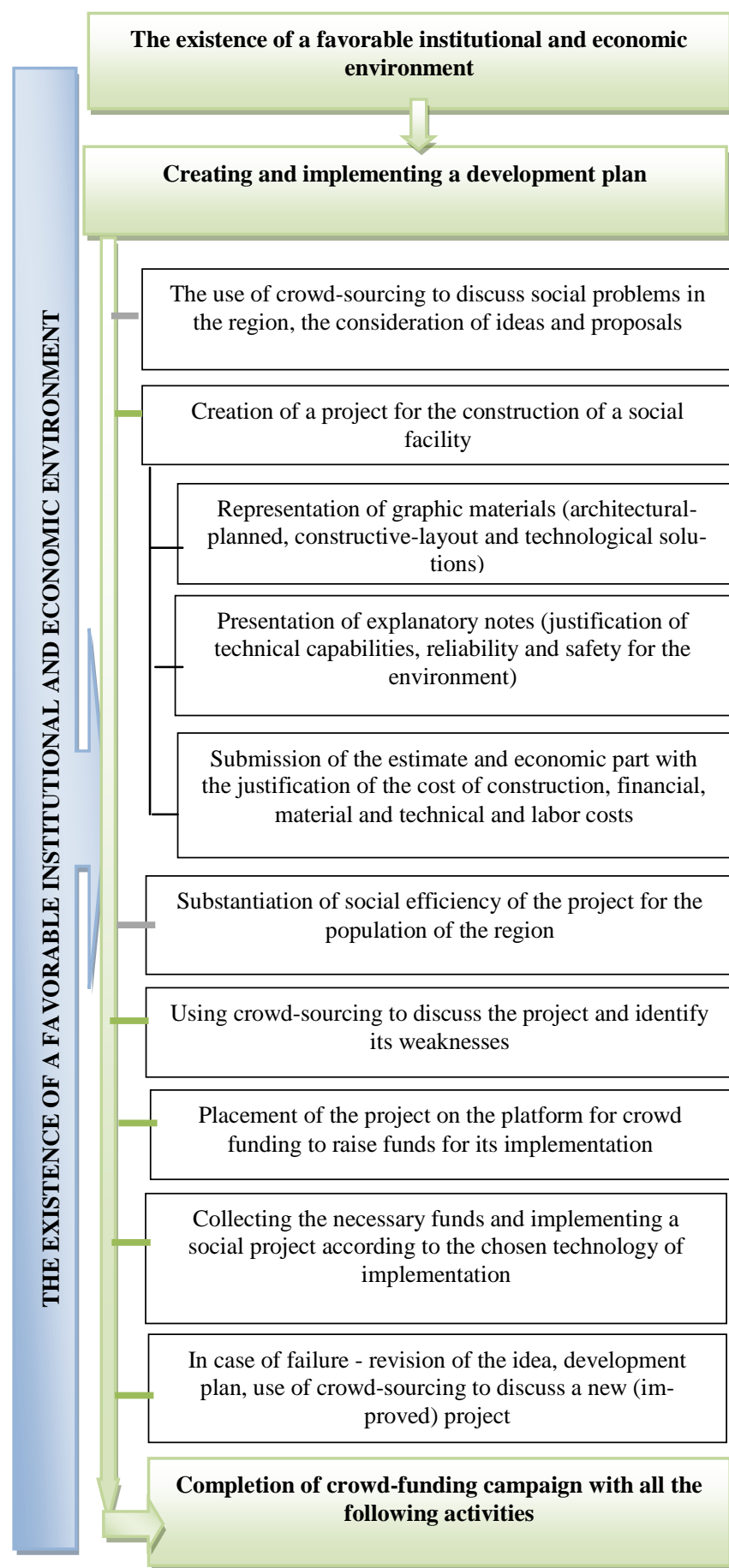

Fig. 1: The organizational mechanism for supporting and implementing projects for the construction of social facilities with the help of crowdhosting platforms: built by the authors

Table 3: Technologies for implementing social projects * constructed and supplemented by authors using materials [13]

\begin{tabular}{|c|c|}
\hline $\begin{array}{l}\text { Type of } \\
\text { Technology }\end{array}$ & Description of the Technology \\
\hline Spot & $\begin{array}{l}\text { It provides for the creation of special experimental facili- } \\
\text { ties or segments with the most favored nation treatment } \\
\text { for the implementation of the social investment project. } \\
\text { Having achieved positive experimental results, the point } \\
\text { zones expand and all new subjects of investment are } \\
\text { involved in the project implementation process. }\end{array}$ \\
\hline Mass & $\begin{array}{l}\text { It presupposes the development of model standards based } \\
\text { on the views of the project developers and investors on } \\
\text { the properties and quality of the social investment prod- } \\
\text { uct. }\end{array}$ \\
\hline Market & $\begin{array}{l}\text { It is based on the market component of the project, the } \\
\text { assumption that the market mechanism is able to regulate } \\
\text { the spontaneous implementation process itself, and the } \\
\text { economic efficiency of the social investment project is }\end{array}$ \\
\hline
\end{tabular}

\begin{tabular}{|l|l|}
\hline & $\begin{array}{l}\text { based, basically, on the profitability of the investment } \\
\text { product. }\end{array}$ \\
\hline Aggressive & $\begin{array}{l}\text { It is characterized by maximum activity in the implemen- } \\
\text { tation of the social investment project by an advertising } \\
\text { campaign in the media, on television and radio, the use of } \\
\text { network marketing with the involvement of a large num- } \\
\text { ber of sellers, the opening of distribution points or the } \\
\text { introduction into existing points of a new product as a } \\
\text { priority. }\end{array}$ \\
\hline Mixed & $\begin{array}{l}\text { It is based on a combination of spot and aggressive. It is } \\
\text { considered as the creation of experimental objects for a } \\
\text { social project, but is accompanied by an active advertis- } \\
\text { ing campaign and crowd-sourcing }\end{array}$ \\
\hline
\end{tabular}

The most successful, in our opinion, can be the mixed technology proposed by the authors of the introduction of a social project, which is a combination of the creation of experimental objects (spot) and implementing projects activity with advertising and crowd-sourcing (aggressive).

At the same time, the important place is taken by the state regulation of social investment using crow-funding, which should be implemented on the basis of the principles of social justice and social and economic efficiency. The purpose of state regulation of crowd-funding activities in the sphere of construction of social facilities should include such aspects as achieving a balance in the interaction of the state, investors and consumers in the process of raising the level and quality of life in the country and its regions.

\section{Conclusion}

In conclusion, we note that crowded framing platforms are more of a communication tool for a social project than a direct source of funding. Correctly conducted crowd-funding company will draw attention to the idea, increasing the chances of a social project to attract the attention of the socially active population and business. With this understanding of crowed-funding, the main indicator of success is the audience and «feedback» that was covered during the campaign, and not the collected funds. In contrast to the population of Western countries, where the construction and implementation of social projects are becoming more widespread and accessible, in our society such practices are single or nonexistent. Therefore, an important and promising issue is the training of active and enterprising people in technologies and prospects for crowd funding for the implementation of investment projects for the construction of social facilities, as well as raising awareness of the benefits and possibilities of crowd-funding for the development of individual territories and regions of the country. This will allow creating objective conditions for the formation of citizens' attitudes towards the socialization of relations in society, involving the population in social activities, which will favorably influence the formation of social culture in society.

\section{References}

[1] Zervoyianni A. «Convergence of Shocks and Trade in the Enlarged European Union», The Rimini Centre for Economic Analysis (2008), $31 \mathrm{pp}$.

[2] Breakdown of Employment Effect by Country. Statistics. European Foundation for the Improvement of Living and Working Conditions, available online: https://www.eurofound.europa.eu/emcc

[3] Douarin Elodie, Mickiewicz Tomasz. Economics of Institutional Change: Central and Eastern Europe Revisited (2017), London, UK DOI 10.1007/978-0-230-29128-7, 319 p.

[4] World happiness report 2017, available online: worldhappiness .report/ed/2017

[5] Sitar L., Skrenkovsky R. «Current state and problems of social sphere of Ukraine». Effective economy (2015), available online: www.economy.nayka.com.ua/ $? \mathrm{op}=1 \& \mathrm{z}=3954$

[6] Lobjanidze Nika. Crowd-funding as a support to Georgian Stock Exchange. Georgian journal (2012), available online: https://www.georgianjournal.ge/

[7] Kickstarter, available online: https://www. kickstarter.com/press?ref=hello 
[8] Suprun N. Socialnoe predprinimatelstvo kak mehanizm razvitiya solidarnoj ekonomiki (2016), Materialy mezhdunarodnogo simpoziuma «Socialnaya i ekonomicheskaya solidarnost - ukrainskij vybor», M., - P. 36-38

[9] Kraudfanding - narodnyie investoryi vseh stran ob'edinyaytes! available online: https://ru.sputnik.az/culture/20160815/406758073.html

[10] Eric Von Hippel (2005), England, available online: http://books.google.com https://evhippel.mit.edu/

[11] Karyy O., Panas Y. (2016). Crowdsourcing as management tool examples of solving local problems. Lviv Polytechnic National University, Institutional Repository, available online: http://ena.lp.edu.ua

[12] Svistun L. «Shemy finansirovaniya developerskih proektov na rynke nedvizhimosti Ukrainy», Ekonomika i region, № 5 (2013), available online: irbis-nbuv.gov.ua. P. 139 - 148.

[13] Yevseyeva A. «Pokazny`ky` efekty`vnosti social`nogo investuvannya», Economics, available online: www.rusnauka. com/6_PNI_2011/Economics /15_74502.doc.htm 